\title{
Perencanaan Knowledge Management System Untuk Tata Kelola Perguruan Tinggi
}

\author{
Supit Mamuaya \\ Magister Manajemen Sistem Informasi \\ Universitas Bina Nusantara \\ Jakarta, Indonesia \\ supitebook@gmail.com \\ Mihuandayani \\ Teknik Informatika \\ STMIK Multicom \\ Bolaang Mongondow, Indonesia \\ mihuandayani20@gmail.com
}

\author{
Harisno \\ Magister Manajemen Sistem Informasi \\ Universitas Bina Nusantara \\ Jakarta, Indonesia \\ harisno@binus.edu \\ Rillya Arundaa \\ Teknik Informatika \\ STMIK Multicom \\ Bolaang Mongondow, Indonesia \\ rill.christy@gmail.com
}

\begin{abstract}
A variety of knowledge, especially for universities in making standards, is one of the important things to be managed and documented. The standard drafting process is carried out by the drafting team in holding meetings and meetings directly. Constraints arise when in the drafting process, the drafting team is difficult to determine the time of meeting the standard discussion directly due to busyness and work constraints. In addition, the unavailability of online media repositories for the PPEPP process is another obstacle because the standard documents that have been discussed are only printed and stored as campus files. This storage process is vulnerable to damage, loss, and sometimes it is difficult to do a search if it is merged with other documents. STMIK Multicom management system is not yet available that can accommodate these knowledge. Thus, to ensure the flexibility and changes of STMIK Multicom to keep up with technological developments, a system that can accommodate individual and organizational knowledge in one portal is needed so that the sharing process becomes easier. The method used in this study is the model of Knowledge Management System Life Cycle (KMSLC). Through a systematic Knowledge Management System application development plan, the results of system testing conducted on respondents as system users obtained results of $81.16 \%$ as the value of benefits for the evaluation of KMS application planning.
\end{abstract} PPEP

Knowledge Management System; University;

Abstrak-Berbagai pengetahuan khususnya bagi Perguruan Tinggi dalam melakukan penyusunan standar merupakan salah satu hal penting untuk dapat dikelola dan didokumentasikan. Proses penyusunan standar dilakukan oleh tim penyusun dengan mengadakan rapat dan pertemuan secara langsung. Kendala muncul ketika dalam proses penyusunannya, tim penyusun sulit menentukan waktu pertemuan pembahasan standar secara langsung disebabkan oleh kesibukan dan kendala pekerjaan. Selain itu, belum tersedianya media repository online untuk proses PPEPP menjadi kendala lainnya sebab dokumen-dokumen standar yang telah dibahas hanya dicetak dan disimpan sebagai arsip dilemari/rak kampus. Proses penyimpanan seperti ini rentan terjadi kerusakan, kehilangan, dan kadang sulit untuk melakukan pencarian jika sudah tergabung dengan dokumen lainnya. STMIK Multicom belum tersedia sistem manajemen yang dapat menampung pengetahuan-pengetahuan tersebut. Sehingga, untuk menjamin fleksibilitas dan perubahan STMIK Multicom demi mengikuti perkembangan teknologi, maka dibutuhkan sebuah sistem yang dapat menampung pengetahuan individu dan organisasi dalam satu portal sehingga proses sharing menjadi lebih mudah. Metode yang digunakan dalam penelitian ini adalah model Knowledge Management System Life Cycle (KMSLC). Melalui perencanaan pengembangan aplikasi Knowledge Management System yang sistematis, hasil pengujian sistem yang dilakukan pada responden sebagai pengguna sistem diperoleh hasil sebesar $81,16 \%$ sebagai nilai manfaat atas evaluasi perencanaan aplikasi KMS.

Keywords-Knowledge Management System; Perguruan Tinggi; PPEPP

\section{PENDAHULUAN}

Pesatnya pertumbuhan data dan teknologi telah memicu transformasi data menjadi informasi yang bernilai yang dikenal sebagai pengetahuan [1]. Saat ini, semakin banyak orang menyadari akan nilai pengetahuan dan berbagai cara untuk mendapatkan, mengenali, menangkap, menyimpan, dan memanfaatkannya, sehingga pengetahuan dapat dibagikan; dengan kata lain bagaimana mengelola pengetahuan [2]. Dekade terakhir, pentingnya pengetahuan telah disorot oleh para akademisi dan praktisi [3]. Pengetahuan menjadi dasar persaingan [4], dan pengetahuan telah menjadi sumber utama bagi kekuatan militer, kekuatan ekonomi bangsa-bangsa serta bidang kehidupan lainnya [5]. Banyaknya pengetahuan yang berlimpah membuat banyak organisasi tumbuh dan berkembang mulai dari berbagai sektor bisnis dalam beberapa tahun ini, tidak terkecuali bidang pendidikan [6]. Sehingga, dapat dikatakan bahwa pengetahuan adalah juga sumber utama bagi kekuatan pendidikan.

Pendidikan tinggi adalah rumah bagi pengetahuan. Dalam dunia pendidikan khususnya universitas, pengetahuan merupakan suatu aset yang begitu penting di mana pengetahuan diciptakan, digunakan, dan disebarkan kepada orang banyak guna untuk kepentingan bersama. Selama bertahun-tahun, manajemen pengetahuan / Knowledge Management (KM) telah menjadi isu utama dalam strategi manajemen di pendidikan tinggi di seluruh dunia, termasuk di negara-negara berkembang. Pendidikan tinggi dianggap berada dalam "bisnis pengetahuan" karena mereka terlibat dalam penciptaan pengetahuan, diseminasi dan pembelajaran [7]. Sistem manajemen perguruan tinggi merupakan sistem yang unik, paduan antara kepentingan akademik dan bisnis jasa pendidikan [8]. Mencermati pentingnya aset pengetahuan dalam organisasi Pendidikan tinggi maka untuk menjaga agar tidak kehilangan pengetahuan tersebut, organisasi perlu mengelola pengetahuan dengan baik. 
Perguruan tinggi, baik negeri maupun swasta dituntut untuk selalu memberikan pelayanan prima kepada civitas akademiknya. Hal ini ditegaskan pemerintah dengan menerbitkan Permenristekdikti No. 44 Tahun 2015 tentang penetapan 24 Standar Nasional Pendidikan Tinggi yang harus dimiliki dan dijalan sebagai inti proses bisnis pendidikan tinggi, yaitu: 1) standar kompetensi lulusan; 2) standar isi pembelajaran; 3) standar proses pembelajaran; 4) standar penilaian pembelajaran; 5) standar dosen dan tenaga kependidikan; 6) standar sarana dan prasarana pembelajaran; 7) standar pengelolaan pembelajaran; 8) standar pembiayaan pembelajaran; 9) standar hasil penelitian; 10) standar isi penelitian; 11) standar proses penelitian; 12) standar penilaian penelitian; 13) standar peneliti; 14) standar sarana prasarana penelitian; 15) standar pengelolaan penelitian; 16) standar pendanaan dan pembiayaan penelitian; 17) standar hasil pengabdian kepada masyarakat; 18) standar isi pengabdian kepada masyarakat; 19) standar proses pengabdian kepada masyarakat; 20) standar penilaian pengabdian kepada masyarakat; 21) standar pelaksana pengabdian kepada masyarakat; 22) standar sarana prasarana pengabdian kepada masyarakat; 23) standar pengelolaan pengabdian kepada masyarakat, dan 24) standar pendanaan dan pembiayaan pengabdian kepada masyarakat.

Keberadaan standar diatas sudah menjadi kebutuhan bagi Sekolah Tinggi Manajemen Informatika dan Komputer Multicom sebagai syarat kelengkapan berkas reakreditasi dibadan akreditasi nasional perguruan tinggi. Proses penyusunan standar dilakukan oleh tim penyusun dengan mengadakan rapat dan pertemuan secara langsung. Kendala muncul ketika dalam proses penyusunannya, tim penyusun sulit menentukan waktu pertemuan pembahasan standar secara langsung disebabkan oleh kesibukan dan kendala pekerjaan. Selain itu, belum tersedianya media repository online untuk proses PPEPP menjadi kendala lainnya sebab dokumen-dokumen standar yang telah dibahas hanya diprint out dan disimpan sebagai arsip dilemari/rak kampus. Proses penyimpanan seperti ini rentan terjadi kerusakan, kehilangan, dan kadang sulit untuk melakukan pencarian jika sudah tergabung dengan dokumen lainnya.

STMIK Multicom dalam pengelolaan telah melibatkan peran teknologi seperti pengelolaan administrasi akademik mengunakan www.stmikmulticom.ac.id. dan pembelajaran online melalui www.ol.stmikmulticom.ac.id. Penerapan eacademic menjadi langkah awal bagi pengelolaan manajemen, pembelajaran dan administrasi yang lebih baik. Dalam proses pengelolaan ini, terdapat banyak pengetahuan yang dibutuhkan dan digunakan. Pengetahuan tersebut sebagian besar masih tersimpan di dalam pikiran setiap individu yang ada di STMIK Multicom.

Pengetahuan yang digunakan dalam proses perkuliahan seperti materi kuliah hanya terbatas di dosen. Pengetahuan tentang pemberkasan hanya diketahui oleh karyawan administrasi tertentu saja dan tidak didokumentasikan dengan baik. Hal ini menyebabkan pengetahuan akan hilang ketika dosen atau karyawan yang menguasai pengetahuan tersebut izin, berhenti, pindah atau pensiun atau tidak bisa digunakan kembali oleh pegawai lainnya sehingga hal ini berdampak pada menurunya kualitas mutu pelayanan STMIK Multicom terhadap mahasiswa. Salah satu penghambat kegiatan operasional serta STMIK Multicom mencapai tujuan organisasi menurut pengamatan kami adalah perbedaan persepsi pemahaman antara satu pegawai dengan pegawai lainnya tentang uraian tugas, SOP, panduan, peraturan dan laporan dari setiap unit kegiatan. Ini terjadi kerena kurang efektifnya sharing pengetahuan dari satu pegawai ke pegawai lainnya yang ada di STMIK Multicom.

Knowledge management membantu sebuah lembaga dalam mengelola pengetahuan sebagai aset, dimana dalam berbagai strateginya ada penyaluran pengetahuan yang tepat kepada orang yang tepat dan dalam waktu yang cepat, hingga mereka bisa saling berinteraksi, berbagi pengetahuan dan mengaplikasikannya dalam pekerjaan sehari-hari demi peningkatan kinerja lembaga [9]. Untuk menjamin fleksibilitas dan perubahan STMIK Multicom demi mengikuti perkembangan teknologi, maka dibutuhkan sebuah sistem yang dapat menampung pengetahuan individu dan organisasi dalam satu portal sehingga proses sharing menjadi lebih mudah.

Di STMIK Multicom belum tersedia sebuah sistem manajemen yang dapat menampung pengetahuanpengetahuan tersebut. Sehingga, dipandang perlu untuk dilakukan pengembangan dan perancangan sistem manajemen pengetahuan. Tujuan penelitian ini yaitu merencanakan pengembangan KMS STMIK Multicom dalam rangka peningkatan kinerja organisasi, yang akan memberikan kontribusi signifikan bagi keunggulan kompetitif organisasi. Dalam penelitian ini, kebaruan yang dihasilkan adalah adanya perumusan pembahasan topik terkait sebagai pemecahan masalah untuk tiga divisi internal yang terlibat. Hasil penelitian ini dimaksudkan untuk mempercepat terjadinya inovasi, penyerapan pengetahuan melalui proses knowledge sharing dan menghasilkan pengetahuan baru sebagai upaya meningkatkan mutu dan daya saing STMIK Multicom. Memudahkan dalam proses sharing peraturan dan tata kelola kampus STMIK Multicom. Bagi tingkat manajerial, bisa menjadi alat bantu perubahan dan inovasi dalam pengembangan STMIK Multicom.

\section{TINJAUAN PUSTAKA}

Penelitian yang membahas tentang knowledge management sistem di universitas yang bertanggung jawab atas pendidikan, penelitian, dan transfer pengetahuan ke masyarakat, sehingga berkontribusi terhadap pembangunan nasional. Tujuan utama penelitian tersebut, yaitu mengajukan model konseptual untuk aplikasi manajemen pengetahuan di universitas-universitas Nigeria. Penelitian ini menyimpulkan bahwa, manajemen pengetahuan memiliki potensi untuk meningkatkan kinerja di dalam universitas, model yang diusulkan harus dikenai validasi empiris untuk amandemen dan perbaikan lebih lanjut [10].

Penelitian terkait knowledge management system yang bertujuan untuk memahami proses, aplikasi, dan peran manajemen pengetahuan di institusi pendidikan. Penelitian tersebut menjelaskan bahwa penerapan praktik pengelolaan pengetahuan di Perguruan Tinggi akan sangat bermanfaat sehingga meningkatkan indikator akademik - pembelajaran siswa, pengembangan kurikulum; tugas administratif \& strategis yang efektif, kualitas penelitian yang lebih baik, pengembangan fakultas yang lebih baik, dan lainnya. Lembaga pendidikan tinggi dapat memanfaatkan teknologi informasi dan membentuk portal dan repositori berbagai jenis informasi internal dan eksternal [11]. 
Dalam penelitian lain yang melakukan analisis penggunaan knowledge management. Analisis dilakukan di antara lima petunjuk yang memberikan manajemen pengetahuan di lembaga pendidikan. Pendekatan yang diikutinya adalah analisis kuantitatif dan subyektif untuk menghitung manajemen pengetahuan. Selain itu, ada perbedaan penting antara kelompok staf akademik dan nonakademik dan hasilnya menunjukkan bahwa institusi pendidikan mengikuti perkembangan menuju pengetahuanorientasi [12].

Penelitian yang menyimpulkan bahwa penggunaan alat digital dalam pendidikan sangat penting untuk penciptaan nilai manajemen pengetahuan bagi peserta dapat terdiri dari berbagai proses yaitu secara tradisional, transfer pengetahuan terjadi dengan bantuan guru secara langsung, atau oleh buku dan catatan. Namun, karena perluasan media online, LMS (Learning Management System) dapat menjadi solusi mutakhir untuk mengelola transmisi pengetahuan. Tujuannya agar sistem ini bisa dimanfaatkan oleh semua guru, pelajar, administrator pada tingkat kelembagaan dalam praktik pendidikan sehari-hari. Dalam kasus ini, sangat penting bahwa pengetahuan karyawan tidak akan hilang pada organisasi. Retensi, kodifikasi, dan transfer pengetahuan dicapai dengan menggunakan alat yang sama [13].

Penelitian membahas tentang pentingnya knowledge management di lingkungan pendidikan. Tujuan penelitian tersebut adalah untuk menganalisis kesiapan institusi pendidikan tinggi di India. Survey yang dilakukan melalui kuesioner dari 540 anggota di fakultas melalui asesmen. Penelitian menghasilkan adanya indikasi yang kuat terhadap dampak positif terkait faktor Knowledge Management Assessment Instrument pada factor Knowledge Management Enablers Scale. Sehingga direkomendasikan untuk meningkatkan knowledge management di organisasi [14].

Penelitian lain membahas tentang hubungan antara knowledge management system, inovasi terbuka, kapasitas manajemen pengetahuan dan kapasitas inovasi. Penelitian tersebut menggunakan pemodelan persamaan structural pada sample 298 perusahaan Italia dari berbagai sektor. Penelitian tersebut menunjukan bahwa KMS memfasilitasi ekosistem terbuka, dan kolaborasi pengetahuan internal dan eksternal melalui pengembangan kapasitas manajemen pengetahuan yang meningkatkan kapasitas inovasi [15].

Studi yang menganalisis aspek - aspek positif dan negatif penggunaan jejaring sosial dalam KMS melalui komponen formal dan informal manajemen suatu organisasi. Hasil membuktikan bahwa perlunya interaksi sosial untuk meningkatkan pengetahuan yang diberikan sebagai efektivitas dalam transmisi pengetahuan secara eksplisit dan implisit [16]. Penelitian terkait yang disebut GeneSys yaitu sistem manajemen pengetahuan eksperimental yang mengeksplorasi isu - isu dalam otomatisasi analisis informasiterutama yang berkaitan dengan hubungan fungsi gen dalam biologi. KMS dapat membantu mengatasi masalah analisis sekumpulan besar informasi sekuens dalam memperoleh fakta - fakta baru serta sebagai alat analisis dan penalaran yang terintegrasi [17].

Penelitian terkait membahas tentang factor - factor penentu penerapan KMS sebagai keunggulan kompetitif organisasi. Penelitian tersebut mengembangkan dan menguji model terintegrasi dari penerapan KMS untuk bisnis dari data 291 bisnis di Taiwan. Hasilnya menunjukan factor invoasi teknologi, faktor organisasi, dan factor lingkungan adalah pengaruh signifikan terhadap implementasi KMS [18]. Penelitian sejenis juga membahas tentang pengembangan KMS pada sejumlah karyawan melalui fitur yang disediakan untuk menyelesaikan sebagian besar pekerjaan. Pendekatan sistematis digunakan untuk menguji fitur dan dampaknya terhadap hasil pekerjaan. Penelitian tersebut menunjukan bahwa model KMS yang diterapkan mampu memberi pengaruh yang signifikan [19].

\section{A. Pengetahuan}

\section{LANDASAN TEORI}

Pengetahuan terdiri atas pengalaman, nilai, wawasan, informasi faktual dan pendapat para pakar yang digunakan untuk membantu evaluasi, menggabungan pengalaman baru, menciptakan pengetahuan baru serta membuat keputusan. Pengetahuan dibagi menjadi dua, yaitu tacit dan explicit [5]. Pengetahuan tacit merupakan pengetahuan yang tersimpan dalam pikiran manusia contohnya pengalaman, wawasan, bakat, dan ide. Pengetahuan explicit adalah pengetahuan yang diekspresikan dalam katakata atau bilangan dan disimpan dalam dokumen atau database.

\section{B. Sistem Manajemen Pengetahuan}

KM adalah teknik membangun lingkungan pembelajaran (learning environment), dimana orang-orang di dalamnya terus termotivasi untuk belajar, memanfaatkan informasi yang ada, dan mau saling berbagi pengetahuan baru yang dihasilkan. KM didasarkan pada pemikiran bahwa, sama seperti manusia tidak dapat memanfaatkan sepenuhnya potensi otak mereka, organisasi pada umumnya tidak dapat sepenuhnya memanfaatkan pengetahuan yang mereka miliki. Melalui KM, organisasi berusaha memperoleh atau menciptakan pengetahuan yang berpotensi berguna dan membuatnya tersedia bagi mereka yang dapat menggunakannya pada satu waktu dan tempat yang sesuai bagi mereka untuk mencapai penggunaan efektif maksimum agar dapat mempengaruhi kinerja organisasi secara positif. Manajemen pengetahuan sangat bergantung kepada empat proses yang didukung oleh tujuh subproses. Empat proses manajemen pengetahuan tersebut berfokus pada bagaimana konversi pengetahuan antara pengetahuan tacit dan pengetahuan eksplisit [20].

KMS merupakan gabungan dari berbagai disiplin ilmu yang masih merupakan bagian dari sistem informasi. KMS mendukung penyimpanan dan akses dokumen dari semua bagian di dalam organisasi. KMS memungkinkan komunikasi secara pasif dari kebijakan, prosedur, dan data dan membantu keberlangsungan dari pengetahuan organisasi [21]. Dengan demikian KMS merupakan salah satu cara yang efektif dalam penyebaran kebijakan dan peraturan dari tingkat atas ke tingkat bawah dalam organisasi [22]. KMS adalah kunci untuk mencapai peluang pengambilan keputusan yang lebih baik dan keunggulan kompetitif bagi organisasi. Sektor akademik memiliki peluang signifikan untuk menerapkan praktik KMS ke dalam misi mereka [23].

\section{KMSLC}

Metode Knowledge Management System Life Cycle (KMSLC) diperkenalkan pada tahun 2010 dengan tahapan pembentukan sistem manajemen pada model ini meliputi [5]: 
1) Evaluate existing infratructure merupakan proses evaluasi keberadaan infrastruktur yang tersedia dan yang dibutuhkan untuk pengembangan sistem; 2) Form the KM team merupakan pembentukan tim, yaitu dengan melakukan identifikasi stakeholder yang kemudian mereka dilibatkan dalam pembuatan sistem manajemen pengetahuan; 3) Knowledge capture merupakan menangkap pengetahuan, yaitu menangkap pengetahuan baik berupa pengetahuan tacit maupun explicit untuk kemudian di dokumentasikan; 4) Design KM blueprint merupakan merancang blueprint sistem, yaitu menggambarkan secara detail mengenai rancangan dari prototype aplikasi sistem manajemenen pengetahuan yang akan dikembangkan; 5) Verify and validate the KM system merupakan menguji pengetahuan, yaitu melihat apakah sistem yang telah dibuat dapat berfungsi dengan baik atau tidak untuk kemudian melakukan perbaikan jika ada kekurangan; 6) Implement KM System menerapkan sistem yang telah dibuat didalam organisasi atau institusi; 7) Manage change merupakan mengelola perubahan; 8) Post system evaluation merupakan evaluasi sistem, yaitu mengukur keberhasilan sistem apakah sudah sesuai dengan tujuan dan kebutuhan pengguna.

\section{A. Pengumpulan Data}

Wawancara dilakukan sebagai upaya menangkap pengetahuan secara tacit dari beberapa responden, terkait sistem menajemen pengetahuan yang mereka inginkan. Ahliahli ini dipilih karena keterlibatan mereka yang sangat intens terhadap pengembangan kampus STMIK Multicom Bolaang Mongondow. Wawancara dilakukan terhadap kepala BAAK STMIK Multicom, Dosen, Staff Administrasi, dan Stakholder. Beberapa catatan penting hasil wawancara adalah sebagai berikut:

1) Kepala BAAK: Membutuhkan sebuah sistem yang dapat menjadi media repository online sehingga dapat memudahkan bagian administrasi dalam mengelola dokumen SOP, SPMI, uraian tugas, panduan, peraturan, dan laporan.

2) Dosen: menginginkan kolaborasi sistem manajemen pengetahuan antar manajemen kampus dan pihak eksternal, yang dituangkan kedalam standard SPMI agar dapat diterapkan untuk perbaikan mutu lulusan. Serta menginginkan sharing dokumen tata kelola kampus.

3) Stakeholders: merupakan individu-individu yang mempunyai peran penting terhadap kebijakan-kebijakan dalam suatu universitas yang mengetahui suatu mekanisme yang berjalan pada lingkungannya.

Selanjutnya, observasi dilakukan dengan melihat dan terlibat secara langsung dalam proses penyusunan dokumen manajemen seperti penyusunan visi, misi, tujuan, dan sasaran, serta penyusunan statuta, renstra, renop, dan rip.

\section{B. Model Manajemen}

Manajemen yang terapkan di Sekolah Tinggi Manajemen Informatika dan Komputer Multicom secara garis besarnya dapat dilihat pada bagan berikut :

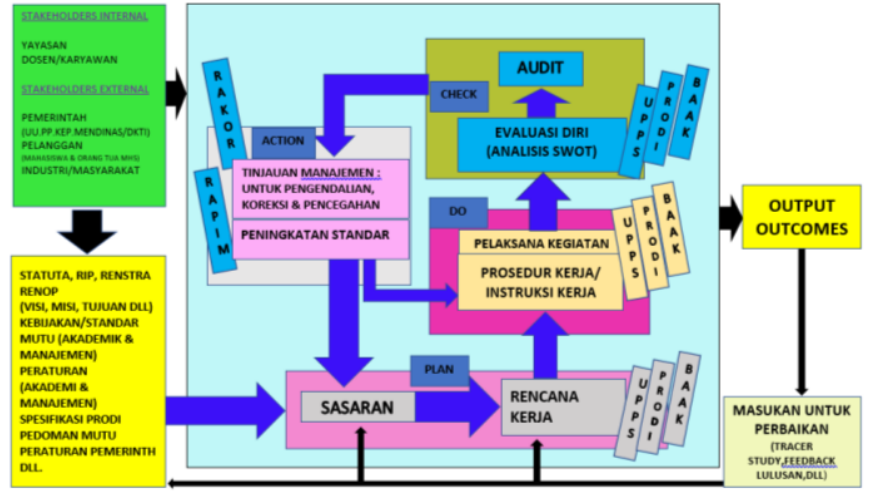

Fig. 1. Model Manajemen STMIK Multicom

Adapun gambar Model Manajemen STMIK Multicom diatas mengandung arti bahwa stakeholder intenal adalah penerima manfaat berupa gaji atau bonus atas kegiatan operasional sedangkan stakeholder eksternal adalah pengguna lulusan/alumni STMIK Multicom. Setelah dilakukan analisa swot terhadap stakeholder maka ditetapkanlah Statuta, RIP, Resntra yang berisi Visi, Misi dan Tujuan menjadi bahan rujukan bersama Permenristekdikti No. 44 Tahun 2015 tentang standar Nasional Pendidikan Tinggi untuk menetapkan Sasaran/Standar pelaksanaan tridharma STMIK Multicom yang akan dicapai dengan rencana kerja dilaksanakan oleh Unit Penyelenggara Program Sudi/Manajemen, Program Studi dan Biro Adminstrasi Akademik dan Keuangan pada akhirnya dilaksanakan evaluasi untuk mengendalikan dan dilaksanakan peningkatan standar sehingga Kebijakan/Standar Mutu, Peraturan Akademik dan Manajemen, Pedoman Mutu, Standar Operasional Prosedur dan Intruksi Kerja akan selalu berkembang dari waktu ke waktu. Ini sejalan dengan Permenristekdikti No. 62 Tahun 2016, tentang Sistem Penjaminan Mutu Pendidikan Tinggi sebagai pedoman pelaksanaan Sistim penjaminan mutu internal dengan siklus PPEPP.

\section{C.Perancangan KMS}

Pengembangan KMS menggunakan pendekatan model Knowledge Management System Life Cycle (KMSLC) dengan tahapan KMSLC pada penelitian ini adalah analisis masalah, akuisisi pengetahuan, perancangan blueprint sistem, verifikasi dan validasi aplikasi KMS, dan terakhir implementasi.

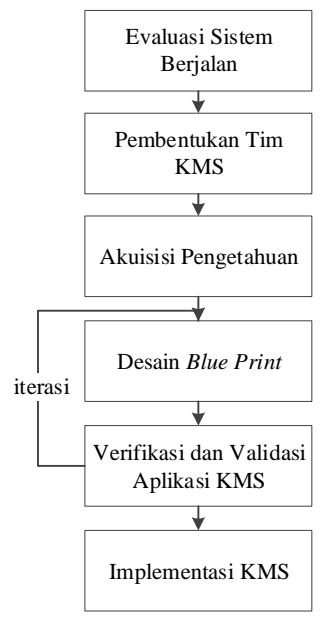

Fig. 2. Tahapan Penelitian KMSLC 


\section{1) Evaluasi Sistem Berjalan}

Tahap ini meliputi analisis masalah dan pengumpulan kebutuhan pembangunan KMS. Analisis dilakukan secara detail terhadap kondisi perusahaan dan mengidentifikasi infrastruktur yang sudah ada di STMIK Multicom, sehingga pengembangan dan perancangan KMS dapat sesuai dengan kebutuhan penerapan KMS. Pointnya terletak pada identifikasi yang akurat dan tepat terhadap apa yang dapat dan tidak dapat dipergunakan sebagai bagian KMS di STMIK Multicom. Hal pertama yang dinalisis adalah teknologi komputer dan infrastuktur jaringan yang berjalan saat ini. Tujuannya adalah untuk mengetahui apakah teknologi dan infrastruktur jaringan saat sudah dapat mendukung penerapan KMS, Dimana memungkinkan untuk peneliti dalam menentukan teknologi infrastruktur usulan yang akan dirancang. Selanjutnya, dilakukan analisis masalah yang terkait dengan pengelolaan manajemen, pembelajaran dan administrasi dianalisis untuk diidentifikasi akar dari permasalahannya. Dari hasil analisis yang dilakukan didapatkanlah suatu rumusan masalah. Penentuan lingkup masalah diambil dari fungsi manajemen pengetahaun yang mencakup ketiga hal yang disebutkan sebelumnya. Analisis juga dilakukan untuk menentukan kebutuhan KMS yang dibangun. Kebutuhan sistem tersebut dideskripsikan dalam kebutuhan fungsional, kebutuhan non fungsional, karakteristik pengguna, kebutuhan antarmuka eksternal, dan lingkungan operasi. Setelah melakukan analisis kebutuhan sistem, dilakukan pula analisis batasan dan deskripsi dari lingkungan arsitektur dari sistem yang dibangun. Selain analisis teknologi dan analisis masalah, dilakukan juga analisis pengguna. Hal ini bertujuan untuk memahami karateristik aktor-aktor yang telibat dalam tata kelola dan sharing pengetahuan yang ada di STMIK Multicom terkait budaya dan sistem tata kelola kampus yang telah dan yang ingin diterapkan. Analisis terhadap stakeholder dilakukan untuk menganalisis kebijakan dan kebutuhan dunia kerja terkait mutu pendidikan yang harus diterapkan dalam tata kelola kampus.

\section{2) Akuisisi Pengetahuan}

Akuisisi pengetahuan adalah proses yang dilakukan untuk menangkap pengetahuan, baik pengetahuan tacit maupun pengetahuan eksplisit [24]. Dalam penelitian ini, metode yang dilakukan dalam menangkap pengetahuan adalah akuisisi pengetahuan tacit dan eksplisit. Pengetahuan tacit dikumpulkan dengan cara wawancara atau diskusi dengan pakar, sedangkan pengetahuan explicit diperoleh dari buku-buku, dan hasil penelitian.

TABLE I. KATEGORI PENGETAHUAN DALAM PENGELOLAAN STMIK MULTICOM

\begin{tabular}{|c|c|c|c|}
\hline \multirow[t]{2}{*}{ No } & \multirow{2}{*}{$\begin{array}{c}\text { Jenis } \\
\text { Pengelolaan }\end{array}$} & \multicolumn{2}{|c|}{ Kategori Knowledge } \\
\hline & & Tacit & Explicit \\
\hline $\mathrm{I}$ & $\begin{array}{l}\text { Pengelolaan } \\
\text { Manajemen }\end{array}$ & $\begin{array}{l}\text { Keterampilan } \\
\text { komunikasi/motivasi } \\
\text { Keceradasan } \\
\text { Emosional/spiritual } \\
\text { Keterampilan } \\
\text { mentransfer } \\
\text { pengalaman } \\
\text { Keterampilan } \\
\text { membangun } \\
\text { kerjasama }\end{array}$ & $\begin{array}{l}\text { Teknik Kepemimpinan } \\
\text { STMIK Multicom } \\
\text { Peraturan yang } \\
\text { berkaitan dengan } \\
\text { STMIK Mulicom } \\
\text { SOP yang berhubungan } \\
\text { dengan } \\
\text { Multicom STMIK } \\
\text { Teori mengajar }\end{array}$ \\
\hline II & $\begin{array}{l}\text { Pengelolaan } \\
\text { Program } \\
\text { Studi }\end{array}$ & $\begin{array}{l}\text { Keterampilan } \\
\text { komunikasi } \\
\text { Keceradasan } \\
\text { Emosional/spiritual } \\
\text { Keterampilan }\end{array}$ & $\begin{array}{l}\text { Teknik Kepemimpinan } \\
\text { Prodi } \\
\text { Peraturan yang } \\
\text { berkaitan dengan Prodi } \\
\text { SOP yang berhubungan }\end{array}$ \\
\hline
\end{tabular}

\begin{tabular}{|c|c|c|c|}
\hline & & $\begin{array}{l}\text { mentransfer } \\
\text { pengalaman }\end{array}$ & $\begin{array}{l}\text { dengan Prodi } \\
\text { Teori mengajar }\end{array}$ \\
\hline III & $\begin{array}{l}\text { Pengelolaan } \\
\text { BAAK }\end{array}$ & $\begin{array}{l}\text { Keterampilan } \\
\text { komunikasi } \\
\text { Keceradasan } \\
\text { Emosional/spiritual } \\
\text { Keterampilan } \\
\text { mentransfer } \\
\text { pengalaman }\end{array}$ & $\begin{array}{l}\text { Teknik Approach } \\
\text { Peraturan yang } \\
\text { berkaitan dengan BAAK } \\
\text { STMIK Multicom } \\
\text { SOP yang berhubungan } \\
\text { dengan BAAK STMIK } \\
\text { Multicom }\end{array}$ \\
\hline
\end{tabular}

\section{3) Desain Blueprint Sistem Manajemen Pengetahuan}

Pengetahuan-pengetahuan yang telah dihimpun pada tahap akuisisi pengetahuan dimodelkan yang hasilnya dimasukkan ke dalam KMS. Hasil analisis masalah dimodelkan dalam bentuk rancangan prototipe dari sistem manajemen pengetahuan yang akan dikembangkan. Pemodelan tersebut direpresentasikan dengan diagram use case, diagram kelas, diagram aktivitas, dan diagram sekuens. Dalam proses penciptaan pengetahuan yang dirumuskan dalam empat pola penciptaan pengetahuan [25], proses tersebut merupakan proses eksplisit ke eksplisit. Dalam hal ini, pengetahuan berbentuk eksplisit yang tersimpan dalam bentuk dokumen digital dikonversi menjadi bentuk pengetahuan eksplisit yang tersimpan dalam KMS. Desain dari prototipe sistem manajemen pengetahuan juga dijelaskan di tahap ini. Hasil dari analisis yang dilakukan pada tahap sebelumnya dimodelkan kembali ke model lanjutan yang merepresentasikan solusi dari sebuah sistem yang dikembangkan. Desain yang dilakukan di tahap ini lebih ditujukan ke penjelasan teknis. Penjelasan desain tersebut meliputi rancangan lingkungan implementasi dan deskripsi fungsional secara rinci. Dari hasil pemodelan yang dilakukan direpresentasikan dengan Interaction Diagram dan Deployment Diagram.

\section{4) Verifikasi dan Validasi Sistem Manajemen Pengetahuan}

Tahap ini terdiri dari dua tahap yaitu implementasi KMS dan pengujian fungsi sistem KMS. Tahap implementasi KMS merupakan proses untuk menuliskan model rancangan KMS yang telah dibuat ke dalam bentuk kode program. KMS dikembangkan berbasis web yang bertujuan agar pengguna dapat memiliki akses kapanpun dan dimanapun. Tahap pengujian fungsi sistem KMS dilakukan dengan menggunakan metode pengujian black box. Pengujian black box biasa disebut juga dengan pengujian fungsional [26]. Dalam pengujian fungsional, pengguna tidak memiliki akses ke rincian internal dari program. Pengguna memberikan suatu masukan dan mengamati hasil eksternal yang diperlihatkan oleh aplikasi. Dari hasil yang diketahui pada tahap pengujian inilah dapat disimpulkan apakah KMS yang dikembangkan siap didistribusikan kepada pengguna KMS.

\section{5) Implementasi $K M S$}

Tahapan ini merupakan deployment sistem yang sudah diuji pada tahap sebelumnya ke internet. Prototipe sistem di implementasikan ke halaman web dengan nama dan domain yang disesuikan dengan kebutuhan STMIK Multicom.

\section{A. Evaluasi Sistem Berjalan}

\section{HASIL DAN PEMBAHASAN}

Pengelolaan pengetahuan di STMIK Multicom Bolaang Mongondow belum terkordinir dengan baik dalam hal pengunaan media yang baik dalam menyimpan, mengelola dan mendistribusikan prosedur-prosedur/kebijakan baku yang dimiliki. Semua prosedur-prosedur yang ada di STMIK 
Multicom tersimpan secara tersebar dimasing-masing komputer pribadi dosen dan karyawan administrasi serta terdapat di ingatan masing-masing dosen dan staff karyawan administrasi. Setiap dosen dan staff adinistrasi mempunyai prosedur, kebiasaan, atau kebijakan masing-masing yang mungkin tidak diketahui oleh bagian lain atau individu didalam organisasi. Ketidaktahuan mengenai prosedur, kebiasaan, atau kebijakan sering menyebabkan masalah/kesalahpahaman apabila mereka melakukan koordinasi pekerjaan antar bagian.

Proses penyimpanan dan pencatatan hasil penyelesaian suatu masalah atau kasus yang terjadi pada proses bisnis tidak diatur secara jelas membuat masing-masing individu menyimpan secara bebas ada yang menyimpan pada laptop, komputer kantor ataupun file sharing yang disediaakan perusahaan. Sehingga menyulitkan bagi karyawan lain yang mengalami suatu masalah atau kasus yang sama pada pelaksanaan proses bisnis. Bentuk pengembangan atau perbaikan proses melalui pengetahuan yang didapat menjadi sulit dikarenakan problem dan masalah yang terjadi sulit teridentifikasi sehingga dari hal tersebut sulit pula dilakukan perbaikan pada proses bisnis inti melalui pengelolaan pengetahuan yang ada. Sistem manajemen pengetahuan yang dikembangkan merupakan sistem manajemen pengetahuan yang dapat memberikan informasi berbasis konten kepada penggunanya. Berbeda dengan sistem pengelolaan manajemen, administrasi, dan prodi di STMIK Multicom sekarang ini yang masih berbasiskan dokumen, sistem ini menawarkan informasi yang fokus kepada isi dan informasi yang berkaitan dengan dokumen tersebut. Pengguna juga mampu melakukan penelusuran terhadap informasiinformasi tersebut. Dokumen yang digunakan dalam KMS SMIK Multicom seperti pada berikut.

TABLE II. DOKUMEN ISI PADA KMS STMIK MULTICOM

\begin{tabular}{|c|c|c|c|}
\hline & Program Studi & Administrasi & Manajemen \\
\hline 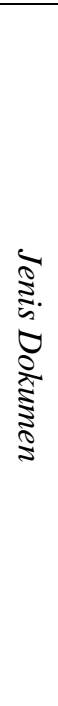 & $\begin{array}{l}\text { Kurikulum } \\
\text { Satuan Acara } \\
\text { Pembelajaran } \\
\text { Silabus } \\
\text { Materi } \\
\text { Perkuliahan } \\
\text { Hasil-hasil } \\
\text { penelitian } \\
\text { Forum-forum } \\
\text { Ilmiah }\end{array}$ & $\begin{array}{l}\text { Tata } \\
\text { penjelasan } \\
\text { kepada calon } \\
\text { mahasiswa } \\
\text { Prosedur } \\
\text { surat masuk- } \\
\text { surat keluar } \\
\text { Prosedur } \\
\text { pembayaran } \\
\text { biaya } \\
\text { perkuliahan } \\
\text { Prosedur } \\
\text { penggunaan } \\
\text { e-academic }\end{array}$ & $\begin{array}{l}\text { Tata tertib kepegawaian } \\
\text { Standar mutu isi } \\
\text { Standar mutu kompetensi } \\
\text { lulusan } \\
\text { Standar mutu penelitian dan } \\
\text { pengembangan } \\
\text { Standar mutu pengabdian } \\
\text { kepada masyarakat } \\
\text { Standar mutu kemahasiswaan } \\
\text { Standar mutu pengembangan } \\
\text { \& fasilitas kampus } \\
\text { Standar mutu dosen \& tenaga } \\
\text { kependidikan } \\
\text { Standar mutu penataan } \\
\text { kelembagaan \& sistem } \\
\text { manajemen } \\
\text { Standar mutu pengembangan } \\
\text { usaha paratan } \\
\text { Standar mutu peningkatan } \\
\text { kesejahteraan } \\
\text { Standar mutu peningkatan } \\
\text { citra STMIK Multicom. }\end{array}$ \\
\hline
\end{tabular}

Dokumen yang diinputkan dan ditampilkan dalam KMS STMIK Multicom haruslah dokumen yang sudah final. Dokumen yang masih berupa revisi tidak diinputkan dalam KMS STMIK Multicom untuk menghindari perbedaan persepsi pengguna. KMS STMIK Multicom dikembangkan berbasis web agar dapat diakses secara publik. Dari analisis terhadap sistem manajemen pengetahuan, dilakukan analisis karakteristik pengguna, kebutuhan sistem, kebutuhan antarmuka eksternal, dan infrastruktur. Maka untuk melakukan analisa pada proses aktifitas inti perusahaan dalam menjalankan bisnisnya dilakukan pengamatan dari kegiatan tersebut. Analisa dari proses digambarkan dengan menggunakan Activity Diagram. Proses-proses yang terjadi pada proses bisnis STMIK Multicom adalah sebagai berikut:

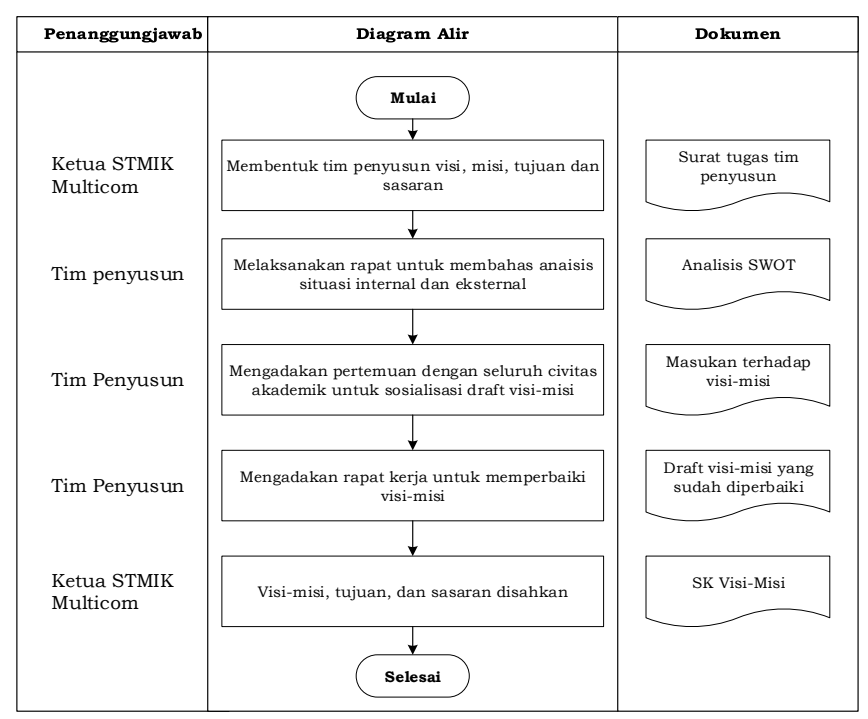

Fig. 3. Proses Penyusunan Dokumen Manajemen (Visi-Misi) STMIK Multicom

Pada Gambar 3 menunjukkan proses penyusunan dokumen manajemen (visi-misi) yang diawali dengan pembentukan tim penyusun oleh Ketua STMIK Multicom dan tim penyusun akan mendapatkan SK berupa surat tugas. Selanjutnya, tim penyusun melaksanakan rapat internal perdana untuk membahas dan menganalisis situasi internal dan eksternal. Proses analisis dilakukan dengan menggunakan analisis SWOT. Setelah melaksanakan rapat internal tim penyusun, dilakukan kembali rapat dengan mengundang seluruh civitas akademika dan stakeholder yang terlibat untuk memberi masukan pada penyusunan visi-misi. Draft visi-misi yang sudah disusun, selanjutnya diperbaiki dan difinalisasi oleh tim penyusun dan tahap terakhir adalah disahkan oleh Ketua STMIK Multicom.

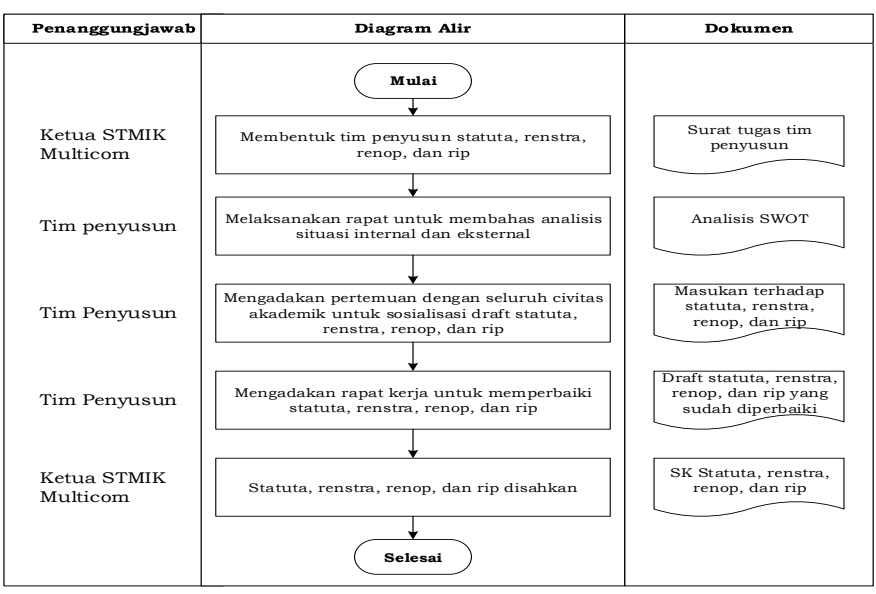

Fig. 4. Proses Penyusunan Dokumen Manajemen (Statuta, Renstra, Renop, dan Rip) STMIK Multicom

Tahapan proses penyusunan statuta, renstra, renop, dan rip sama dengan tahapan penyusunan visi-misi. Gambar 4 
menunjukkan proses penyusunan dokumen manajemen (statuta, renstra, renop, dan rip) yang diawali dengan pembentukan tim penyusun oleh Ketua STMIK Multicom dan tim penyusun akan mendapatkan SK berupa surat tugas. Rapat perdana dilaksanakan secara internal tim penyusun untuk membahas dan menganalisis situasi internal dan eksternal menggunakan analisis SWOT. Rapat kedua dilasanakan secara terbuka, yaitu dengan mengundang seluruh civitas akademika dan stakeholder yang terlibat untuk memberi masukan pada penyusunan visi-misi. Draft visi-misi yang sudah disusun, selanjutnya diperbaiki dan difinalisasi oleh tim penyusun dan tahap terakhir adalah disahkan oleh Ketua STMIK Multicom.

\begin{tabular}{|c|c|c|}
\hline Penanggungjawab & Diagram Alir & Dokumen \\
\hline & Mulai & \\
\hline $\begin{array}{l}\text { Ketua STMIK } \\
\text { Multicom }\end{array}$ & Membentuk tim penyusun SPMI & $\begin{array}{l}\text { Surat tugas tim } \\
\text { penyusun }\end{array}$ \\
\hline & $\downarrow$ & \\
\hline Tim penyusun & $\begin{array}{c}\text { Melaksanakan rapat untuk membahas analisis } \\
\text { situasi internal dan eksternal }\end{array}$ & Analisis SWOT \\
\hline Tim Penyusun & \begin{tabular}{|c|}
$\downarrow$ \\
$\begin{array}{c}\text { Mengadakan pertemuan dengan seluruh civitas } \\
\text { akademik untuk sosialisasi draft SPMI }\end{array}$
\end{tabular} & $\begin{array}{l}\text { Masukan terhadap } \\
\text { draft SPMI }\end{array}$ \\
\hline Tim Penyusun & Mengadakan rapat kerja untuk menyusun SPMI & $\begin{array}{l}\text { Draft SPMI yang } \\
\text { sudah disusun }\end{array}$ \\
\hline $\begin{array}{l}\text { Ketua STMIK } \\
\text { Multicom }\end{array}$ & Mengesahkan dokumen SPMI & SK SPMI \\
\hline & $\underset{\text { Selesai }}{\downarrow}$ & \\
\hline
\end{tabular}

Fig. 5. Proses Penyusunan Dokumen SPMI STMIK Multicom

Tahapan proses penyusunan SPMI juga sama dengan tahapan penyusunan visi-misi. Gambar 5 menunjukkan proses penyusunan dokumen manajemen (SPMI) yang diawali dengan pembentukan tim penyusun oleh Ketua STMIK Multicom dan tim penyusun akan mendapatkan SK berupa surat tugas. Rapat perdana dilaksanakan secara internal tim penyusun untuk membahas dan menganalisis situasi internal dan eksternal menggunakan analisis SWOT. Rapat kedua dilasanakan secara terbuka, yaitu dengan mengundang seluruh civitas akademika dan stakeholder yang terlibat untuk memberi masukan pada penyusunan visi-misi. Draft visi-misi yang sudah disusun, selanjutnya diperbaiki dan difinalisasi oleh tim penyusun dan tahap terakhir adalah disahkan oleh Ketua STMIK Multicom.

\section{B. Perancangan Diagram}

Diagram use case KMS STMIK Multicom untuk user Admin ditunjukkan seperti pada Gambar 6.

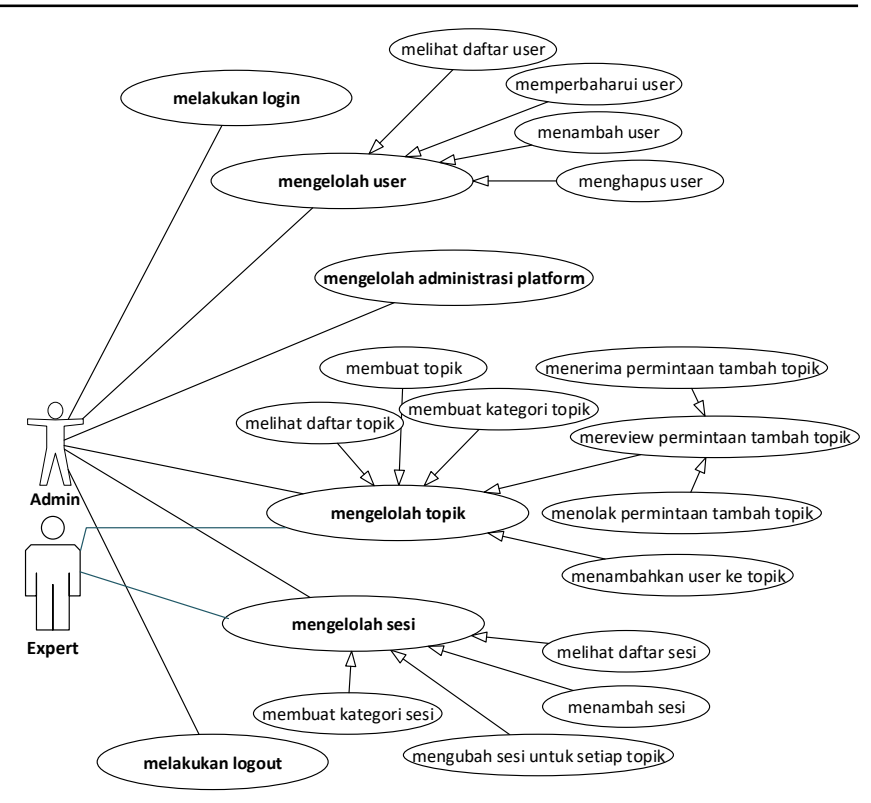

Fig. 6. Diagram Use Case Admin

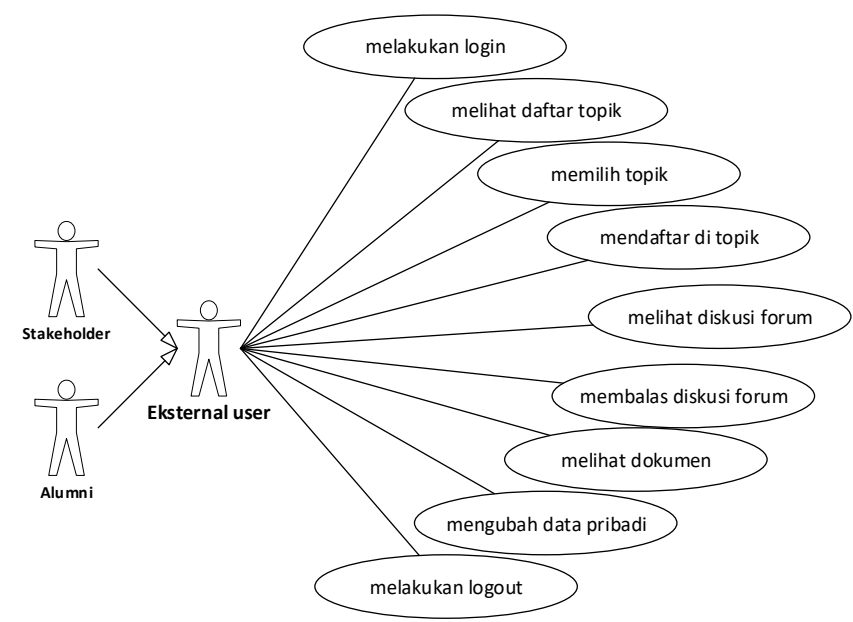

Fig. 7. Diagram Use Case External User

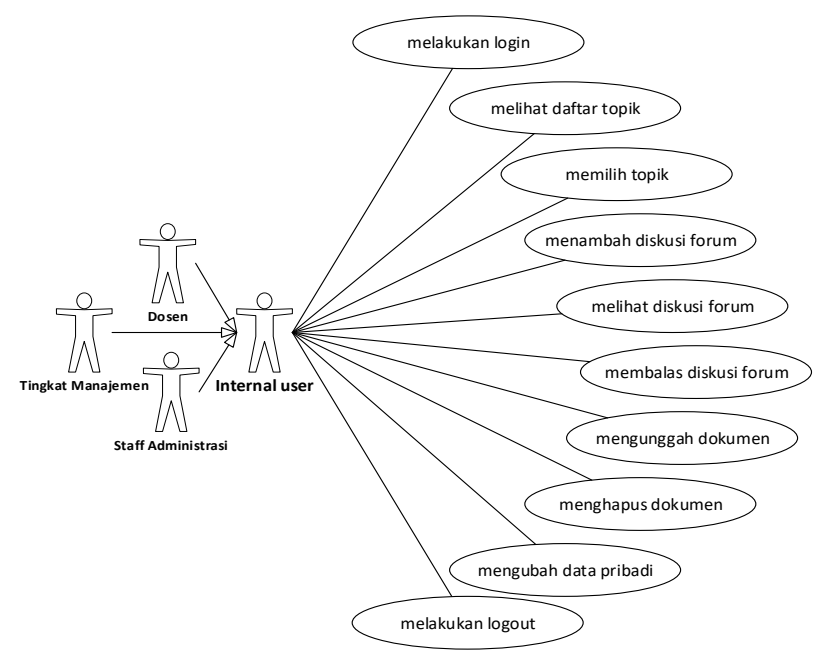

Fig. 8. Diagram Use Case Internal User 


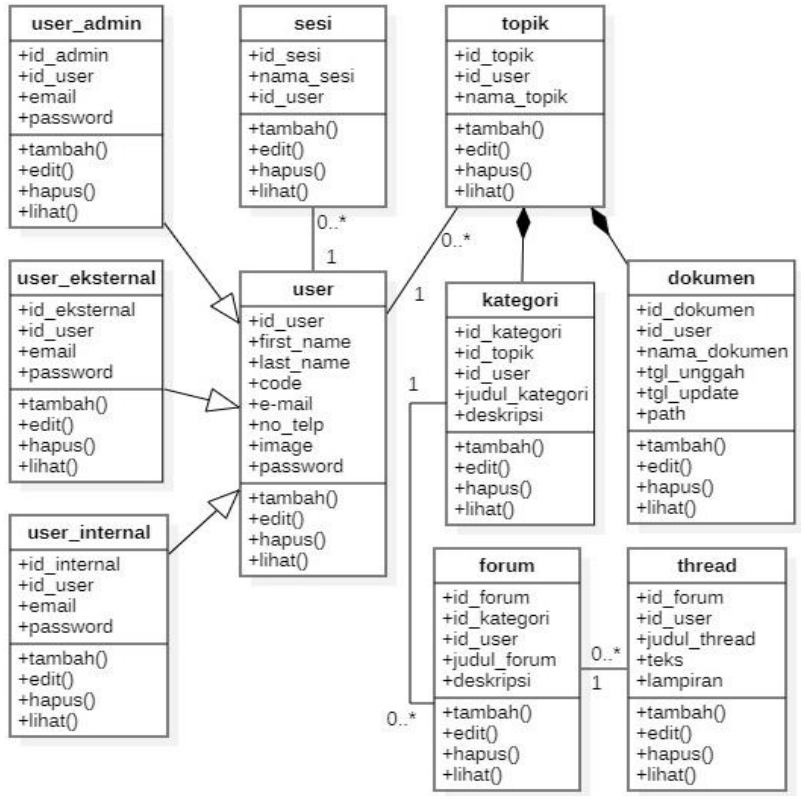

Fig. 9. Class Diagram KMS STMIK Multicom

Berdasarkan dengan kebutuhan yang ada, arsitetur sistem pendukung manajemen pengetahuan digambarkan dengan model yang diusulkan pada gambar berikut:

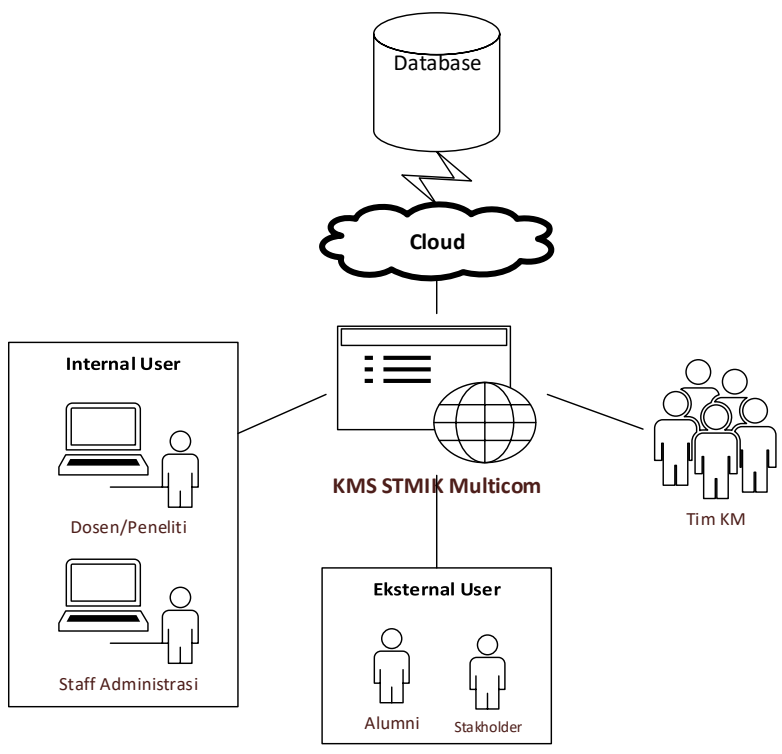

Fig. 10. Arsitektur Sistem KMS STMIK Multicom

\section{Hasil Evaluasi KMS}

Responden dari kusioner evaluasi adalah bagian : Manajerial, Biro Administrasi Akademik dan Keuangan (BAAK), dan Program Studi dengan jumlah responden 12 orang. Manajerial, Biro Administrasi Akademik dan Keuangan (BAAK), dan Program Studi menjadi bagian penting dalam penggunaan aplikasi Knowledge Management System ini, sehingga diperlukan masukan dan evaluasi terhadap proses knowledge sharing menggunakan aplikasi. Responden dilatih menjalankan aplikasi KMS dengan mengakses berbagai menu dan fitur yang dirancang untuk kemudian diminta responnya dengan mengisi kuesioner. Pertanyaan-pertanyaan yang disusun bersifat tertutup dengan pilihan jawaban dalam bentuk skala Likert. Untuk lebih jelasnya bisa dilihat pada lampiran kuesioner evaluasi aplikasi knowledge management system dari setiap pertanyaan yang ada.

TABLE III. DAFTAR RESPONDEN

\begin{tabular}{|l|l|c|c|}
\hline No & \multicolumn{1}{|c|}{ Responden } & Jumlah & Persentase \\
\hline 1 & Manajerial & 3 & $25,0 \%$ \\
\hline 2 & $\begin{array}{l}\text { Biro Administrasi } \\
\text { Akademik dan } \\
\text { Keuangan (BAAK) }\end{array}$ & 5 & $41,7 \%$ \\
\hline 3 & Program Studi & 4 & $33,3 \%$ \\
\hline \multicolumn{2}{|l|}{ Jumlah } & 12 & $100.00 \%$ \\
\hline
\end{tabular}

Berdasarkan tabel III dapat dilihat frekuensi responden bagian Manajerial sebanyak 3 orang atau $25 \%$, bagian BAAK sebanyak 5 orang atau 41,7 \%, dan Program Studi sebanyak 4 orang atau 33,3\%. Hasil jawaban dari responden pada kuesioner dianalisa untuk memperoleh kesimpulan mengenai efektivitas aplikasi KMS, apakah tujuan dan manfaat dari aplikasi KMS tercapai. Hasil analisa kuesioner dapat dilihat pada tabel di bawah ini :

TABLE IV. HASIL ANALISAS KUESIONER EVALUASI APLIKASI KMS

\begin{tabular}{|c|c|c|c|c|c|c|c|}
\hline \multirow[t]{2}{*}{ No } & \multirow[t]{2}{*}{ Pertanyaan } & \multicolumn{6}{|c|}{$\begin{array}{l}\text { Jumlah Responden yang } \\
\text { Memilih }\end{array}$} \\
\hline & & 1 & 2 & 3 & 4 & 5 & Sub Total \\
\hline 1 & $\begin{array}{l}\text { Apakah } \\
\text { Knowledge } \\
\text { Management System } \\
\text { ini mudah dipahami } \\
\text { dan digunakan? }\end{array}$ & 0 & 0 & 2 & 7 & 3 & 49 \\
\hline 2 & $\begin{array}{l}\text { Fitur Diskusi Forum } \\
\text { dan Repository apakah } \\
\text { membantu anda } \\
\text { menuangkan ide dan } \\
\text { knowledge sharing? }\end{array}$ & 0 & 0 & 0 & 8 & 4 & 52 \\
\hline 3 & $\begin{array}{l}\text { Aplikasi Knowledge } \\
\text { Management } \\
\begin{array}{l}\text { ini, apakah stem } \\
\text { efektif }\end{array} \\
\text { pendokumentasian } \\
\text { SOP dan kebijakan, } \\
\text { laporan, dokumen yang } \\
\text { lain serta kasus-kasus } \\
\text { atau masalah yang } \\
\text { pernah terjadi dapat } \\
\text { lebih mudah diakses } \\
\text { dan dicari? }\end{array}$ & 0 & 0 & 3 & 6 & 3 & 48 \\
\hline 4 & $\begin{array}{l}\text { Apakah fitur dan } \\
\text { susunan menu yang } \\
\text { ada pada aplikasi KMS } \\
\text { ini telah efektif sebagai } \\
\text { suatu sarana online } \\
\text { sharing? }\end{array}$ & 0 & 0 & 3 & 7 & 2 & 47 \\
\hline 5 & $\begin{array}{lr}\text { Knowledge } & \text { yang } \\
\text { tersimpan di dalam } \\
\text { aplikasi KMS ini } \\
\text { apakah sudah efektif } \\
\text { untuk menambah } \\
\text { pengetahuan dan dalam } \\
\text { membantu pencarian } \\
\text { dokumen? }\end{array}$ & 0 & 0 & 1 & 9 & 2 & 49 \\
\hline 6 & $\begin{array}{lr}\text { Dokumentasi } & \text { solusi } \\
\text { dari setiap kasus atau } & \text { katkah } \\
\text { masalah } & \text { dapatak } \\
\text { dijadikan referensi } & \text { dalam menyelesaikan } \\
\text { kasus atau masalah } \\
\text { serupa? }\end{array}$ & 0 & 0 & 4 & 5 & 3 & 47 \\
\hline
\end{tabular}




\begin{tabular}{|c|c|c|c|c|c|c|c|}
\hline 7 & $\begin{array}{lr}\text { Apakah } & \text { aplikasi } \\
\text { Knowledge } & \\
\text { Management System } \\
\text { ini, efektif dalam } \\
\text { mendukung suatu } \\
\text { budaya Knowledge } \\
\text { Sharing dalam berbagi } \\
\text { pengetahuan? }\end{array}$ & 0 & 0 & 0 & 6 & 6 & 54 \\
\hline 8 & $\begin{array}{lr}\text { Apakah } & \text { fitur } \\
\text { Repository } & \text { dapat } \\
\text { digunakan } & \text { dengan } \\
\text { mudah? } & \\
\end{array}$ & 0 & 1 & 3 & 5 & 3 & 46 \\
\hline 9 & $\begin{array}{lr}\text { Apakah fitur Forum, } \\
\text { membantu } \\
\text { berbagi informasi dan } \\
\text { knowledge r untuk } \\
\text { memenuhi kebutuhan } \\
\text { anda? }\end{array}$ & 0 & 0 & 2 & 7 & 3 & 49 \\
\hline 10 & $\begin{array}{l}\text { Apakah menu yang ada } \\
\text { pada aplikasi } \\
\text { Knowledge } \\
\text { Management System } \\
\text { ini sudah efektif } \\
\text { memenuhi kebutuhan } \\
\text { anda? }\end{array}$ & 0 & 1 & 4 & 3 & 4 & 46 \\
\hline \multicolumn{7}{|c|}{ Total } & 487 \\
\hline \multicolumn{7}{|c|}{ Rata-Rata Nilai Responden } & 40,58 \\
\hline
\end{tabular}

Nilai hasil kuesioner yang diperoleh adalah 40,58 (didapat dari 487/12 = 40,58) artimya berada di atas nilai rata-rata efektif, sehinga dapat disimpulkan aplikasi KMS ini sudah dapat memenuhi sebesar $81,16 \%$ (didapat dari $40,58 / 50=81,16 \%$ ) dari tujuan dan manfaat. Persentase didapat dari rata-rata nilai responden 40,58 dibagi dengan nilai yang sangat efektif 50 dan dikalikan dengan $100 \%$. Sisanya 18,84\% (didapat dari 100\%-81,16\%) mengindikasikan tujuan dan manfaat aplikasi KMS belum dapat terpenuhi diantaranya dapat disebabkan oleh kurangnya sosialisasi fungsi dan cara penggunaan aplikasi KMS dan perlu adanya penyempurnaan fungsi-fungsi dari perintah pada aplikasi KMS.

\section{KESIMPULAN DAN SARAN}

Kesimpulan yang diperoleh dari perancangan aplikasi knowledge management STMIK Multicom adalah perancangan aplikasi KMS STMIK Multicom dikembangkan dengan menggunakan aplikasi CMS Chamillo dan berfokus pada strategi codification untuk memungkinkan penyimpanan dan penggunaan kembali knowledge. Aplikasi KMS STMIK Multicom dapat memfasilitasi user internal dan user eksternal dalam berbagi penngetahuan dan mengoptimalkan penggunaanya dengan menyediakan manajemen dokumen untuk berbagai keperluan seperti dokumen manajemen standar dan fitur forum diskusi. Aplikasi KMS STMIK Multicom dapat menyimpan pengetahuan yang ada di STMIK Multicom dan pengalaman karyawan dan stakholder yang bermanfaat baik pada saat ini ataupun di masa yang akan datang. Dengan penggunaan aplikasi KMS STMIK Multicom dapat mengakomodasi waktu rapat, karena dapat dilakukan melalui diskusi forum di aplikasi. Selain itu dapat pula mengurangi waktu yang dibutuhkan untuk mencari dikumen yang terkait topik-topik tertentu. Karena dapat melihat pada dokumen yang sudah tersimpan atau pengetahuan yang sudah tersimpan. Dengan terbitnya surat keputusan Ketua STMIK Multicom Nomor 113 Tahun 2019 tentang penggunaan www.kms.stmikmulticom.ac.id sebagai Website pengelolaan
Knowledge Manajemen system Sekolah Tinggi Manajemen Informatika dan Komputer Multicom menandakan bahwa aplikasinya telah berjalan dengan baik.

Adapun saran dalam penelitian ini yaitu manajemen harus berperan serta dalam melakukan sosialisasi akan pentingnya pengetahuan dan mendukung penggunaan aplikasi KMS STMIK Multicom. Tim KM sebagai admin aplikasi KMS STMIK Multicom perlu melakukan perawatan terhadap alikasi dan pengetauan yang disimpan agar tetap up-to-date dan dapat digunakan secara optimal. Tim KM dapat melakukan pengembangan aplikasi KMS STMIK Multicom dengan menambahkan fitur ratin untuk memonitor aktivitas dan partisipasi pengguna internal dan eksternal, sehingga dapat diketahui user yang paling aktif dan berhak mendapat reward dari pihak kampus.

\section{PENGHARGAAN}

Ucapan terima kasih kepada STMIK Multicom Bolaang Mongondow atas dukungan selama pengembangan penelitian ini.

\section{REFERENSI}

[1] Laal, M. (2011). Knowledge Maanagement in Higher Education. Elsevier, 544-549.

[2] Ismail, M. A., \& Yang, C. L. (2007, 01 01). Implication of Knowledge Management $(K M)$ in Higher Learning Institution. Dipetik 0814 , 2017, dari Kmtalk: www.kmtalk.net/article.php?story $=20070507214335110$

[3] Wu, I., \& Lin, H. (2009). A Strategy-based Process for Implementing Knowledge Management: An Integrative View and Imperical Study. Journal of the American Society for Information Science and Technologi, 60(4), 789-802.

[4] Emadzade, M. K., Mashayekhi, B., \& Abdar, E. (2012, March). Knowledge Management Capabilities and Organizational Performance. Interdisciplinary Journal of Contemporary Research in Business, 3(11), 781-790.

[5] Awad, E. M., \& Ghaziri, H. M. (2010). Knowledge Management: 2nd Edition. USA: Prentice Hall.

[6] Ibrahim, F. (2015). Pengembangan sistem pendukung manajemen pengetahuan antar universitas (studi kasus IPB dan UNPAK). Bogor: Institut Pertanian Bogor.

[7] Savitri, F., Sahiraliani, D., \& Yakhusna, R. (2013). Knowledge management implementation within the higher education institutions in Bandung, Indonesia's city of education. South East Asia Journal of Contemporary Business, Economics and Law, 59-63.

[8] Budiastuti, D. (2012). Model knowledge management di perguruan tinggi. Binus Business Review, 52-60.

[9] Retnoningsih, E. (2013, September). Knowledge Management System (KMS) dalam Meningkatkan Inovasi LPPM Perguruan Tinggi. Evolusi, 1(1), 76-85.

[10] Ojo, A. (2016). Knowledge management in Nigerian universities: A conceptual model. Interdisciplinary Journal of Information, Knowledge, and Management, 331-345.

[11] Sharma, M. K., \& Kaur, M. (2016). Knowledge Management in Higher Education. International Journal of Management \& Social Sciences, 548-555.

[12] Mohammad, M., \& Jose, G. J. (2016). An analysis of knowledge management in educational institution. International Journal of Applied Sciences and Management, 211-218.

[13] Balogh, A. P. (2014). The Role of E-Learning in the Knowledge Management System if Higher Education Institutions. Szent Istvan University, School of Management and Business Administration. Budapest: Szent Istvan University.

[14] Kumaravel, V., \& Vikkraman, P. (2018). Assessment of Knowledge Management Practices in Higher Educational Institutions in India: A Structural Equation Modeling Approach. International Journal Education and Science, 20(1-3): 120-136. DOI: 10.1080/09751122.2017.1423192. 
[15] Santoro, G., Vrontis, D., Thrassou, A., \& Dezi, L. (2018). The Internet of Things: Building a knowledge management system for open innovation and knowledge management capacity. Technological Forecasting and Social Change 136, 347-354.

[16] Oseledchik, M., Ivleva, M., \& Ivlev, V. (2018). Using Social Networks in Knowledge Management System. $2^{\text {nd }}$ International Conference on Culture, Education and Economic Development of Modern Society (ICCESE 2018).

[17] Overton, GC., Koile, K., \& Pastor, JA. (2018). GeneSys: A Knowledge Management System for Molecular Biology. Computers and DNA, 213-239.

[18] Wang, YM., \& Wang, YC. (2016). Determinants of firms' knowledge management system implementation: an empirical study. Computers in Human Behavior 64, 829-842.

[19] Xiaojun, Z. (2017). Knowledge Management System Use and Job Performance: A Multilevel Contingency Model. MIS Quarterly 41 (3).

[20] Becerra-Fernandez, I., \& Sabherwal, R. (2010). Knowledge Management: systema and Processes. New York: M. E. Sharpe.

[21] Satzinger, J. W., Jackson, R. B., \& Burd, S. D. (2012). Systems Analysis and Design in a Changing World (6ed). Boston, MA (US): Course Technology, Cengage Learning.

[22] Putra, P. C. (2016). Pengembangan Sistem Manajemen Pengetahuan Berbasis Ontologi Dan Semantic Network Untuk Pengelolaan Standard Operating Procedure IPB. Bogor: Institut Pertanian Bogor.
[23] Ramakrishnan, K., \& Yasin, N. M. (2012). Knowledge management system and higher education institutions. International Conference on Information and Network Technology (ICINT) (hal. 67-71). Singapore: IACSIT Press.

[24] Stollberg, M., Zhdanova, A. V., \& Fensel, D. (2004, March). A Next Generation Knowledge Management Platform. Journal of Information \& Knowledge Management, 45-66.

[25] Nonaka, I., \& Takeuchi, H. (1995). The Knowledge-creating Company: How Japanese Companies Create the Dynamics of Innovation. New York: Oxford University Press.

[26] Nidhra, S., \& Dondeti, J. (2012, June). Black box and white box testing techniques-a literature review. International Journal of Embedded Systems and Applications, 2(2), 29-50. 